\title{
APRENDER FAZENDO: BREVE RELATO DE EXPERIÊNCIA A PARTIR DO ESTÁGIO SUPERVISIONADO EM GEOGRAFIA (UNIMONTES)
}

\author{
LEARNING BY DOING: BRIEF EXPERIENCE REPORT FROM \\ THE SUPERVISED INTERNSHIP IN GEOGRAPHY \\ (UNIMONTES)
}

Amanda Karolayne Rodrigues Silva ${ }^{1}$ Letícia Gonçalves Silva Santos ${ }^{1}$ Maria Heloisa Pinheiro Dias ${ }^{1}$ Vitória Caroline Vidal ${ }^{1}$ Rahyan de Carvalho Alves ${ }^{2}$

\section{RESUMO}

O Estágio Supervisionado visa aprimorar o ensino acadêmico para graduar profissionais da educação com excelência, proporcionando o desenvolvimento da teoria aliada à prática no ambiente escolar. $\mathrm{O}$ presente artigo tem por objetivo ressaltar a importância do estágio na formação docente e descrever as experiências vivenciadas, as atividades e os resultados obtidos de intervenções realizadas durante o estágio supervisionado em Geografia da Universidade Estadual de Montes Claros - UNIMONTES, desenvolvidas nas escolas: Escola Municipal Professora Maria de Lourdes, Escola Estadual João de Deus e Escola Estadual Eloy Pereira, situadas em Montes Claros e em Francisco Sá, Minas Gerais, no ano de 2019. O caminho metodológico realizado consistiu em análise bibliográfica, observação crítica da estrutura física das escolas e regências em turmas do $6^{\circ}$ e $7^{\circ}$ anos com o desenvolvimento de atividades dinâmicas. Diante as experiências vivenciadas, considera-se que o estágio é um espaço de construção de saberes e conhecimentos da realidade escolar que propicia a troca de experiências entre o licenciando e o professor regente e orientador, articulação entre a teoria e a prática e a respectiva aplicação de metodologias e didáticas aprendidas no curso, aperfeiçoamento da desenvoltura na sala de aula e construção da identidade docente.

Palavras-chave: Estágio. Geografia Escolar. Formação Docente.

\section{ABSTRACT}

The Supervised Internship aims to improve academic education to graduate education professionals with excellence, providing the development of theory combined with practice in the school environment. This article aims to emphasize the importance of the internship in teacher education and describe the experiences, activities

\footnotetext{
${ }^{1}$ Acadêmicas do curso de Geografia - Licenciatura Plena - da Universidade Estadual de Montes Claros, Unimontes.

${ }^{2}$ Professor da Universidade Estadual de Montes Claros, Unimontes.

E-mail: rahyan.alves@unimontes.br
} 
and results obtained from interventions carried out during the supervised internship in Geography at the Universidade Estadual de Montes Claros - UNIMONTES, developed in schools: Municipal School Professor Maria de Lourdes, State School João de Deus and State School Eloy Pereira, located in Montes Claros and Francisco Sá, Minas Gerais, in 2019. The methodological path carried out consisted of bibliographic analysis, critical observation of the physical structure of schools and conductors in 6th and 7th grade classes with the development of dynamic activities. In view of the experiences, it is concluded that the internship is a space for building knowledge and knowledge of the school reality that allows the exchange of experiences between the licensee and the conducting teacher and advisor, articulation between theory and practice and the respective application methodologies and didactics learned in the course, improvement of resourcefulness in the classroom and construction of the teaching identity.

Keywords: Phase. School Geography. Teacher Education.

\section{INTRODUÇÃO}

O Estágio Supervisionado em Geografia, componente curricular da licenciatura, visa aprimorar o ensino acadêmico para graduar profissionais da educação com excelência, proporcionando o desenvolvimento da teoria aliada à prática no ambiente escolar. (MATIAZO; BERNARDINO, 2016).

O estágio consta na Lei $\mathrm{n}^{\circ} 11.788$, de 25 de setembro de 2008 - Artigo $1^{\circ}$, que o define como:

Um ato educativo escolar supervisionado, desenvolvido no ambiente de trabalho, que visa à preparação para o trabalho produtivo de educandos que estejam frequentando o ensino regular em instituições de educação superior, de educação profissional, de ensino médio, da educação especial e dos anos finais do ensino fundamental, na modalidade profissional da educação de jovens e adultos. (BRASIL, LEI N ${ }^{\circ} 11.788 / 2008$ ).

Atribui-se ao estágio contribuições diversas aos formandos da licenciatura por instigálos a refletir sobre a prática docente através da aproximação com o docente - do ensino básico e da universidade. Dessa forma, "a aprendizagem da profissão docente ocorre por meio da partilha dos saberes da experiência dos professores-regentes e da prática reflexiva mediada pelos professores-orientadores de estágio.” (BARBOSA; ROCHA, 2014, p. 4)

O diálogo entre o professor-orientador e o professor-regente propicia a partilha das experiências com os docentes em formação, além de auxiliarem no desenvolvimento de atividades a serem trabalhadas no período regencial e esclarecer sobre possíveis estratégias a serem adotadas frente aos desafios cotidianos do exercício da profissão.

Em conformidade com Barbosa e Rocha (2014, p. 1), ambos os profissionais “[...] desempenham papéis importantes na troca de experiências e construção de conhecimentos, compreensão e busca de alternativas para melhoria do ensino da educação básica.” A prática do estágio é um espaço de reflexão de ações propositivas que podem vir a transformar o ensino-aprendizagem da escola pública. 
Martins e Tonini (2016) ressaltam que:

O papel do estágio supervisionado é o de proporcionar a articulação entre conhecimentos teóricos e práticos e o desenvolvimento de estratégias e habilidades para lidar com as situações em sala de aula. Deve caracterizar-se como espaço de reflexão sobre aspectos teórico-práticos do processo ensino-aprendizagem, possibilitando ações propositivas capazes de dar conta dos desafios colocados pela docência. A teoria tem importância fundamental na formação, pois dota os professores de condições atuantes, de forma crítica e contextualizada, oferecendolhes perspectivas sobre como compreender os diversos contextos vivenciados por eles. (pp. 103-104)

A fundamentação teórica norteia os aspectos a serem analisados no desenvolvimento do estágio, a citar a aplicação de metodologias atentando-se à sua eficácia e adequação de acordo com as especificidades da cultura escolar. Ao proporcionar a vivência da prática docente, o estágio contribui para a construção da identidade docente, pois conforme destacado por Pimenta (1999, p. 18):

[...] Espera-se, pois, que mobilize os conhecimentos de teoria da educação e da didática necessários à compreensão do ensino como realidade social, e que desenvolva neles a capacidade de investigar a própria atividade para, a partir dela, constituírem e transformarem os seus saberes-fazeres docentes, num processo contínuo de construção de suas identidades como professores.

O contato com o campo de atuação profissional proporcionado pelo estágio suscita reflexões ao licenciando em Geografia referente ao domínio do saber teórico-prático da disciplina específica e da área da Educação. Além do mais, este se habitua ao manejo de recursos e materiais didáticos diversos, ofertados pela escola, valendo-se de sua criatividade e motivação em elaborar aulas atrativas aos educandos.

O licenciando compreendendo que o aprimoramento profissional é obtido com dedicação e com anos de prática, tem no estágio a oportunidade de trabalhar metodologias aprendidas no decorrer do curso, adaptá-las ao contexto ou até mesmo inová-las em prol da educação de qualidade nas escolas públicas.

Nessa perspectiva, este artigo tem por objetivo ressaltar a importância do estágio na formação docente e descrever as experiências vivenciadas, as atividades e os resultados obtidos de intervenções realizadas durante o estágio supervisionado da graduação em Geografia da Universidade Estadual de Montes Claros - UNIMONTES, desenvolvidas nas escolas: Escola Municipal Professora Maria de Lourdes, Escola Estadual João de Deus e Escola Estadual Eloy Pereira, situadas em Montes Claros e em Francisco Sá, Minas Gerais, em 2019.

O caminho metodológico realizado consistiu em: 
a) análise bibliográfica da temática Estágio Supervisionado em Geografia, pautandose nos seguintes autores: Pimenta (1999), Martins e Tonini (2016), entre outros.

b) observação da estrutura física das escolas a fim de analisar se oportunizavam espaços propícios ao desenvolvimento pleno do processo de ensino-aprendizagem dos alunos;

c) observação dos alunos das escolas supramencionadas para a elaboração de metodologias de ensino de acordo com a realidade social na qual estavam inseridos.

d) regência em turmas do $6^{\circ}$ e $7^{\circ}$ anos do ensino fundamental, acompanhadas pelo professor-regente e professor-orientador, com aplicação de atividades relacionadas aos conteúdos de localização e representação do espaço e população.

O artigo está organizado em três tópicos: no primeiro, ressalta-se a importância do estágio supervisionado na formação docente; no segundo, apresenta-se as atividades desenvolvidas nas escolas e os resultados; e no terceiro, pondera-se sobre as experiências dos estagiários, as dificuldades e desafios no exercício da prática docente.

\section{Resultados e Discussão}

O estágio supervisionado realizado obedece às normas estabelecidas no Regulamento do Estágio Curricular Obrigatório do Curso de Geografia (Deliberação n ${ }^{\circ}$ 042/2007), em conformidade com o Regulamento Geral de Estágio de Graduação da Universidade Estadual de Montes Claros - UNIMONTES.

Os procedimentos documentais e as instruções para a o desenvolvimento do estágio foram esclarecidas pelo professor-orientador, Rahyan de Carvalho Alves, da disciplina Estágio Supervisionado em Geografia, aos licenciandos do $5^{\circ}$ período em Geografia da Universidade Estadual de Montes Claros - UNIMONTES.

As orientações e esclarecimento assemelham-se a uma bússola que norteia o estagiário nessa etapa fundamental da formação docente. Segundo Felício e Oliveira (2008, p. 217), “[...] o estágio curricular se bem fundamentado, estruturado e orientado, configura-se como um momento de relevante importância no processo de formação dos futuros professores".

Pimenta e Lima $(2005 ; 2006)$ defendem que o estágio é importante para os futuros professores aperfeiçoarem os saberes e conhecimentos sobre o contexto escolar e do processo de ensino e aprendizagem. A regência de classe abrange o planejamento, avaliação, relação aluno/professor, entre outras etapas basilares da formação do licenciando, conforme destacado por Moura (2011, p. 3)

No formato de regência de classe, o estágio é compreendido como um campo de conhecimento próprio e um método investigativo que envolve a reflexão e a intervenção na escola, e tem como principal desdobramento a produção de um novo saber, em que o planejamento ocupa posição de destaque, por apresentar-se como 
estratégia didática e subsídio formativo para uma proposta desafiante, ousada e entrelaçada com as necessidades concretas da escola.

O planejamento docente envolve os objetivos, competências e habilidades, conteúdo e a avaliação no âmbito da formação inicial "como uma forma de garantir a excelência nas atividades realizadas neste importante período de regência” (MOURA, 2011, p.1).

Além do mais, a partir da regência o acadêmico conquista paulatinamente confiança e desenvoltura frente à turma e compreende que o ofício vai além do aspecto teórico, abrangendo metodologias e didáticas que devem instigar o aluno a criatividade e o senso crítico, já que o professor é responsável tanto por mediar o conhecimento quanto a formar cidadãos conscientes e críticos nas esferas social e política.

Nessa direção, descreve-se as experiências vivenciadas no desenvolvimento do estágio e as observações in loco das respectivas escolas: Escola Municipal Professora Maria de Lourdes, Escola Estadual João de Deus e Escola Estadual Eloy Pereira, afim analisar criticamente as condições do espaço físico educativo e suas implicações no ensinoaprendizagem.

A Escola Municipal Professora Maria de Lourdes - MG, localizada no bairro Independência, atende às séries iniciais do $1^{\circ}$ ao $5^{\circ}$ ano, no período vespertino e às séries finais do $6^{\circ}$ ao $9^{\circ}$ ano no período matutino. A escola tem cerca de 1.153 crianças de acordo com o censo escolar de 2018.

Quanto à infraestrutura, a escola possui sala de direção, secretaria, sala dos professores, laboratório de informática, sala de apoio especial, quadra de esportes coberta, cantina, refeitório, biblioteca e banheiros sanitários. Tem água filtrada, água da rede pública, energia da rede pública, rede de esgoto e coleta de lixo periódica.

Os professores trabalham com o livro didático para as crianças terem acesso aos conteúdos, o livro não é a única forma de transmitir o conhecimento, são propostas atividades baseadas nos eixos de forma lúdica, através de brincadeiras. As professoras que trabalham na instituição possuem o curso superior, os demais funcionários como secretária e serviços gerais possuem o ensino médio completo.

Durante o estágio observou-se que em certas turmas a relação professor e aluno era conturbada devido a indisciplina dos alunos, mas também em outras foi observado muita interação, participação, afeto e carência, entre as crianças com o professor.

O estágio divide-se em duas etapas: observação e regência. As regências eram realizadas com a avaliação dos professor-regente e professor-orientador referente ao desempenho na sala de aula. Desenvolveu-se atividades com vídeos, esquemas, textos e perguntas afim de verificar se o conteúdo foi apreendido pelo aluno. 
No final verificou-se o quão significativas são as atividades planejadas e pensadas no processo de aprendizagem do aluno e o quanto os alunos correspondem de maneira positiva o que desenvolvem em sala de aula.

A Escola Estadual João de Deus Dias, situada na cidade de Francisco Sá, atende alunos das séries do $6^{\circ}$ ou $9^{\circ}$ ano no período matutino e $1^{\circ}$ ao $5^{\circ}$ ano no período vespertino. Caracterizando a estrutura física da escola tem salas amplas, com mesas e cadeiras apropriadas, sala de vídeo, biblioteca que disponibiliza livros didáticos, cantina, sala dos professores e sala da secretaria. Entretanto, não possui quadro branco e quadra esportiva para realização das aulas de educação física.

Notou-se que o contato da escola e os familiares dos alunos ocorrem apenas em reuniões com os responsáveis dos alunos no final de bimestre (4) para a entrega dos boletins. Os funcionários possuem competência em manter os alunos mais disciplinados, além de exercer seu comprometimento em seus cargos desenvolvidos. A equipe diretiva da escola busca sempre suprir as necessidades dos materiais escolares e participando ativamente do cotidiano para o bom andamento escolar. Os membros que compõem a gestão escolar são: a diretora, vice-diretora, supervisora, professores, funcionários responsáveis pela limpeza, coordenadores e professores de apoio.

$\mathrm{Na}$ regência trabalhou-se o eixo temático: localização e representação do espaço. $\mathrm{O}$ objetivo consistiu em introduzir o aluno às noções e conceitos básicos de Geografia para permitir a compreensão do espaço que está inserido.

Após o esclarecimento da importância da cartografia na orientação espacial, aplicou-se uma atividade em que os alunos deveriam identificar os pontos cardeais e colaterais., conforme destacado na Figura 01.

Figura 01. Atividade aplicada aos alunos sobre a Rosa dos Ventos.

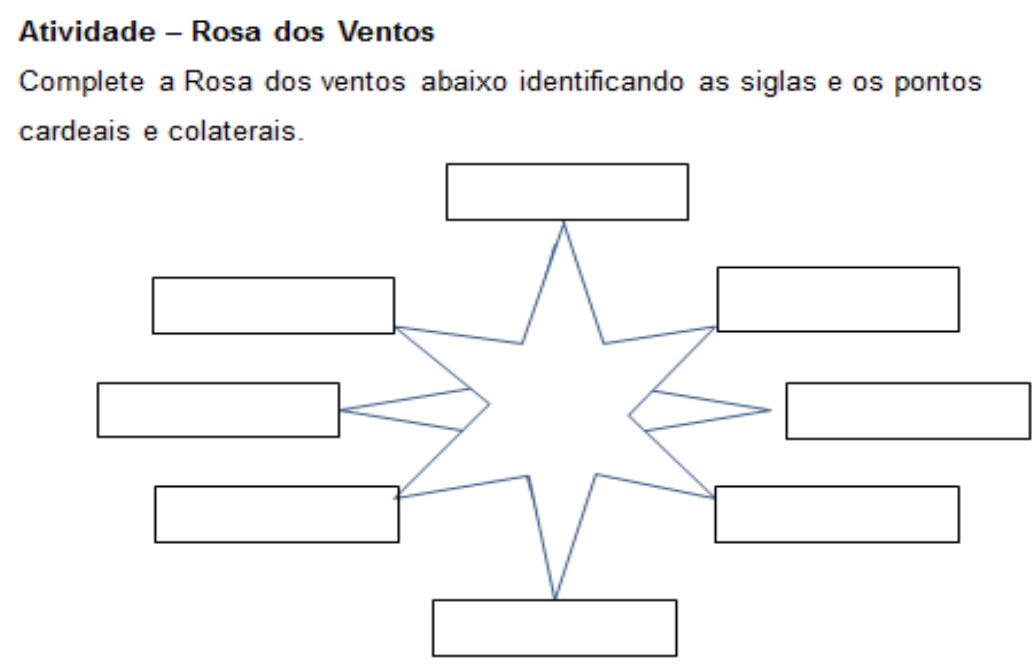


Por meio desta atividade, objetivou-se analisar se os alunos haviam apreendido o conteúdo ministrado, com a conclusão, realizou-se a correção juntamente aos alunos. Pontouse a importância da orientação espacial no cotidiano, articulando a teoria com a realidade para facilitar o aprendizado e torná-lo mais efetivo. A partir do desenvolvimento desta atividade, o estagiário aprende sobre a dinâmica em sala de aula e como atrair a atenção dos alunos, estimulando sua participação.

Contudo, ocorreram alguns contratempos no desenvolvimento das aulas. Alguns alunos se apresentavam indisciplinados, com mau comportamento e desinteresse. Além disso, outro ponto que cabe ressaltar como desafio constitui na relação de identificar as dificuldades encontradas aos fatos que atrapalham alguns alunos de aprenderem.

A Escola Estadual Eloy Pereira localizada no bairro Vila Guilhermina, na cidade de Montes Claros, oferece como suporte para os professores materiais e serviços como impressão, fotocópia, materiais de papelaria (cola, fita adesiva, cartolina, folha A4, pincel, tinta para recarga, entre outros), data show, sala de vídeo, laboratório de ciência e informática, embora a utilização de tal laboratório tenha sido presenciada apenas uma vez no período em que ocorreu o estágio. Possui biblioteca, que disponibiliza para os alunos livros didáticos e literários e espaço para pesquisa; também disponibiliza quadra coberta para prática de esportes e outros eventos e atende à demanda do $6^{\circ}$ ano do ensino Fundamental ao $3^{\circ}$ ano do ensino Médio.

A supervisora da escola mostrou-se bastante ativa e atenta às deficiências dos alunos e frequentemente junto com a coordenação elaborou trabalhos e projetos que envolveu toda a comunidade escolar e, sobretudo os adolescentes, como jogos internos, Feira de Ciências, teatros, palestras e outros trabalhos como confecção de cartazes sobre assuntos da atualidade, como: depressão, gravidez na adolescência, drogas, entre outros.

Embora a escola apresente essa infraestrutura, ainda está muito aquém do necessário para que o aluno desenvolva todo o seu potencial, além de não possuir recursos ou infraestrutura adequados para atender a alunos com necessidades especiais.

Apesar do laboratório de informática e do acesso à internet, essas tecnologias são pouco exploradas e não há uma integração entre professor/aluno, ensino/aprendizagem e tecnologias. Essa falta de interação, de estímulo e de adesão se torna um entrave para o desenvolvimento pleno destes alunos.

O direito de aprendizagem e desenvolvimento através do uso de tecnologias está disposto na competência geral 5 da BNCC - Base Nacional Comum Curricular: 
as escolares) para se comunicar, acessar e disseminar informações, produzir conhecimentos, resolver problemas e exercer protagonismo e autoria na vida pessoal e coletiva. (BNCC, 2018, p. 85).

Outra questão percebida durante o estágio foi o baixo nível de aprendizagem dos alunos dos sétimos anos. O conhecimento deles em relação aos conteúdos básicos da disciplina de Geografia está defasado e essa deficiência torna impossível o desenvolvimento de um cidadão com autonomia e posicionamento crítico, ficando explícita a necessidade de uma investigação e intervenção pedagógica para melhorar o desempenho desses alunos levando em consideração as suas limitações e particularidades. Ainda assim, segundo o Índice de Desenvolvimento da Educação Básica - IDEB, o nível de aprovação para os alunos do $7^{\circ}$ ano do Ensino Fundamental foi de 74,2\% em 2017.

Resende (2000) afirma que ao longo da história, o "fracasso" ou insucesso escolar faz parte da realidade do ensino no Brasil. Há muito tempo, as crianças e adolescentes apresentam uma história marcada por rupturas e reprovações.

Os principais desafios enquanto estagiário foi lidar com os distintos perfis dos alunos, a indisciplina de alguns e, em consequência, a dificuldade para ministrar a aula planejada dentro do tempo disponível.

Os livros adotados para os sétimos anos foram: Projeto Araribá (Professor), organizado pela editora Moderna e Geografia: espaço e vivência - Organização do espaço brasileiro, da editora Saraiva (Levon Boligian, et al, 2016).

Quanto ao conteúdo esclarecido em sala de aula, foi trabalhado com os alunos dos sétimos anos "azul" e "verde" a temática: "População Brasileira", cujos objetivos eram compreender a formação da população brasileira considerando os fatores étnico-culturais e analisar como esta população está distribuída pelo território considerando os aspectos naturais, históricos e econômicos.

As aulas foram realizadas na sala de vídeo, onde foi utilizado o data show para exibição de slides que ilustravam mapas, gráficos, pirâmides etárias e textos explicativos sobre: população relativa e absoluta de alguns países em comparação ao Brasil; as diferentes formas de ocupação do espaço e o porquê de isso acontecer; os fatores que influenciam na distribuição das populações e os indicadores estatísticos da dinâmica populacional entre outros, sendo que todos esses dados foram retirados dos livros supracitados. A Figura 02 ilustra a apresentação do gráfico sobre a evolução da população residente no país. 
Figura 02. Aula ministrada no estágio - tema população.

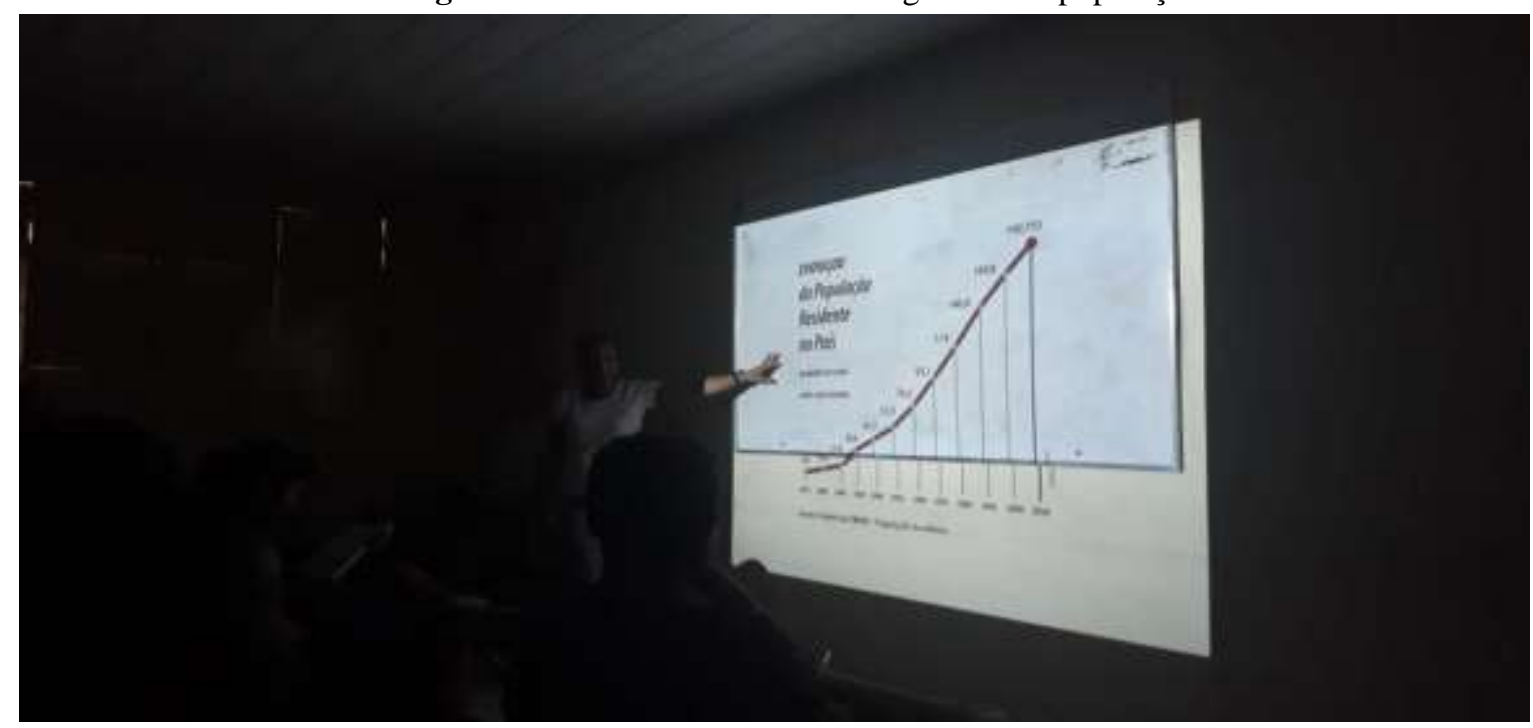

FONTE: Próprio autores, 2019.

A figura 2 ilustra a estagiária explicando o conteúdo à turma na sala de vídeo, quando a realização da aula ocorre em ambientes diferentes da sala de aula, geralmente, os alunos mostram-se mais interessados e participativos.

O estágio supervisionado oportuniza ao licenciando aplicar práticas pedagógicas inovadoras apreendidas no decorrer do curso, dessa forma rompendo com a sucessão de aulas monótonas com quadro e giz, desenvolvendo aulas dinâmicas com recursos didáticos variados e em ambientes diversos, como a sala de vídeo, biblioteca, quadra, sala de informática, entre outros, explorando o espaço escolar e atraindo a atenção dos alunos, implicando em uma melhor aprendizagem.

Prosseguindo a aula, discutiu-se com os alunos sobre a distribuição desigual da população dentro do território brasileiro utilizando mapas, conforme a Figura 03.

Figura 03. Aula ministrada no estágio - distribuição da população.

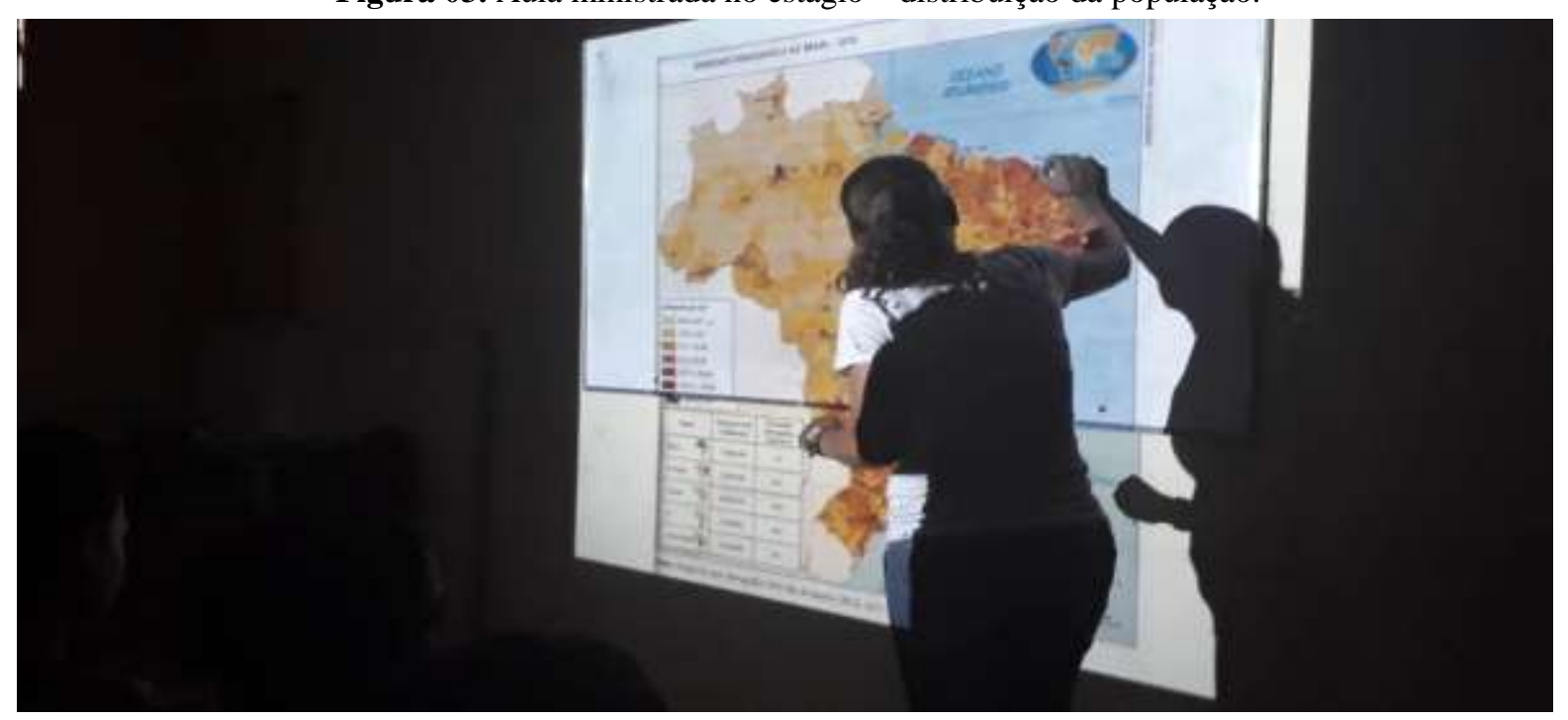

FONTE: Próprio autores, 2019. 
Trabalhar com mapas é primordial no ensino de Geografia por ensinar os alunos a se localizarem e a lerem criticamente o espaço. A utilização deles em sala de aula instiga os alunos a realizarem apontamentos e questionamentos pertinentes à compreensão do conteúdo ministrado, por isso, os docentes e aqueles que estão em formação não devem deixar de lançar mão deste recurso didático para o bom desenvolvimento do ensino-aprendizagem.

Entre as atividades realizadas, destaca-se o exercício utilizando o jogo PalavrasCruzadas projetado no quadro branco. Os alunos deveriam responder às questões dispostas e, de acordo com os acertos, recebiam uma premiação simbólica (bombom) para motivá-los a interagir e participar da atividade,tendo como resultado um número de acertos significativos. As Palavras-Cruzadas e as respectivas questões estão ilustradas na Figura 04.

Figura 04. Palavras Cruzadas

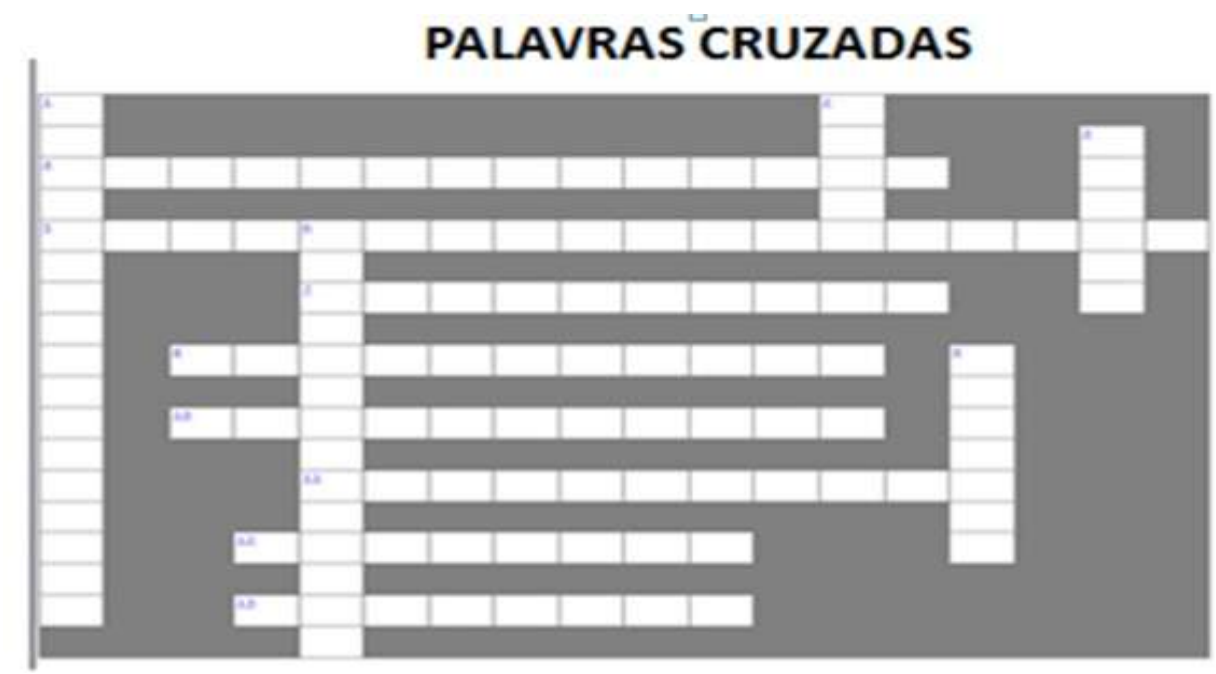

FONTE: Elaboração própria baseada em dados do livro didático - "Projeto Araribá 7ª ano", 2016.

1-É o mesmo que esperança de vida ao nascer. Corresponde a quantos anos, em média, as pessoas viverão.

2- Se localiza na Ásia e é o país mais populoso do mundo, com 1.354.146.443 hab.

3-É o segundo menor país em extensão territorial, ficando atrás apenas do Vaticano, mas é o país mais povoado do mundo

4-É um tipo de gráfico que representa os dados sobre a população masculina e feminina, por idade

5-É a diferença entre a taxa de natalidade e a taxa de mortalidade em um determinado período 6-O seu maior uso pelas mulheres resultou em redução significativa na taxa de fecundidade

7- É a taxa que indica o número de nascimentos em cada grupo de mil habitantes, num determinado período

8-É a taxa que indica o número de óbitos em cada grupo de mil habitantes 
9-País Trata-se da população relativa de um país (densidade demográfica), ou seja, o número de habitantes que residem em uma determinada área 10- É a taxa que indica o número médio de filhos por mulher em idade entre 15 e 49 anos. 11- Tem o seu equilíbrio afetado quando há um maior número de aposentados do que de população jovem economicamente ativa.

12-Inclui tanto a imigração quanto a emigração e interfere na taxa de crescimento populacional.

13- País trata-se da população total ou absoluta de um determinado país.

Diante as experiências vivenciadas, considera-se que o estágio é um espaço de construção de saberes e conhecimentos da realidade escolar que propicia a troca de experiências entre o licenciando e o professor regente e orientador, articulação entre a teoria e a prática e a respectiva aplicação de metodologias e didáticas aprendidas no curso, aperfeiçoamento da desenvoltura na sala de aula e construção da identidade docente. Frente ao exposto, reafirma-se a importância do estágio supervisionado na formação docente para a transformação do ensino público brasileiro.

\section{Considerações Finais}

Embora as experiências do Estágio Curricular Supervisionado tenham ocorrido em contextos e realidades escolares distintas, as estagiárias em questão chegam à comum conclusão da importância do mesmo para a formação do profissional. Há plena convicção de que a teoria e a prática são indissociáveis e ambas possibilitaram o amadurecimento, um maior desenvolvimento pessoal e intelectual e comprometimento com a educação pública. $\mathrm{O}$ período do estágio mostrou inúmeras fragilidades nas escolas e deficiências no ensino que comprometem e inviabilizam uma educação efetivamente de qualidade, que atenda às necessidades dos alunos e professores das redes públicas.

Ficou nítido para as estagiárias, a necessidade de intervenção não apenas do governo, mas de toda a sociedade para melhoria na qualidade do ensino, na infraestrutura das escolas, na formação dos professores e na formação pessoal dos alunos a fim de se tornarem cidadãos conscientes e com poder de argumentação.

Portanto, a prática do estágio trouxe contribuições para nosso saber, foi uma possibilidade de amadurecimento tanto pessoal, quanto profissional, pois ao nos relacionarmos com os alunos foi preciso colocar em prática a ética, o respeito e a interação com os demais profissionais para o bom desenvolvimento no ambiente de trabalho. Apesar dos pontos negativos vivenciados durante o estágio, de maneira geral pode-se concluir que a 
experiência foi positiva e edificante e, juntamente com a teoria se caracteriza como importante fundamento para alicerçar nossa vida profissional.

\section{REFERÊNCIAS}

ALVES, A. B. et al. Geografia - Espaço e Vivência - $7^{\circ}$ ano. Ed. Saraiva, 2019.

BARBOSA, M. E. S.; ROCHA, L. B. Estágio supervisionado em geografia: oportunidade de reflexão sobre o espaço escolar. In: Endipe, 17., 2014, Fortaleza. Anais... didática e a prática de ensino nas relações entre escola, formação de professores e sociedade. Fortaleza: EdUECE, 2014. v. 1. pp. 1-5.

BNCC. Base Nacional referência 2018/2019. Disponível em: $\langle$ http://basenacionalcomum.mec.gov.br/implementacao/praticas $>$. Acesso em: 10 outubro de 2019.

BRASIL. Lei $\mathbf{n}^{\circ}$ 11.788, de 25 de novembro de 2008. Disponível em: <http://www.planalto.gov.br/ccivil_03/_ato2007-2010/2008/lei/111788.htm>. Acesso em: 20 de fevereiro de 2020.

EDU. 2018. Indicadores da $\quad$ educação. Disponível em: <https://www.qedu.org.br/escola/157839-escola-municipal-professora-maria-de-lourdespinheiro/censo-escolar>Acesso em: 09 de outubro de 2019.

FELÍ́CIO, H. M. dos; OLIVEIRA, R. A. de. A formação prática de professores no estágio curricular. Educar, Curitiba, n. 32, p. 215-232, 2008.

IDEB. 2018. Indicadores da educação. Disponível em: < http://idebescola.inep.gov.br/ideb $>$. Acesso em: 10 de outubro de 2019.

MAGAlHÃES, C, et al. Projeto Apoema Geografia 6. $2^{\circ}$ ed. São Paulo: Editora do Brasil, 2015.

MATIAZO, S.; BERNARDINO, V. M. P. A Importância do estágio curricular supervisionado em Geografia para a formação de docentes: uma proposta pedagógica. In: Encontro Regional de Ensino de Geografia, 5., 2016, Campinas. Anais... Encontro Regional de Ensino de Geografia, Campinas: ERES, 2016. pp. 1-12.

MARTINS, R. E. M. W; TONINI, I. M. A importância do estágio supervisionado em Geografia na construção do saber/fazer docente. Geografia Ensino \& Pesquisa, V. 20, N. 3, pp. 98-106, 2016.

MOURA, J. D. P. O Estágio na Formação do Professor de Geografia. 2011. (Apresentação de Trabalho/Comunicação). Disponível em: <http://www.uel.br/revistas/prodocenciafope/pages/arquivos/JEANI\%20MOURA\%20\%20GEOGRAFIA.pdf> Acesso em: 18 de novembro de 2019.

PIMENTA, S. G. Saberes pedagógicos e atividade docente. São Paulo: Cortez Editora, 1999. 
PIMENTA, S. G.; LIMA, M. S. L. Estágio e docência: diferentes concepções. Revista Poíesis, [s. n.], v. 3, n. 3, pp. 5-24, 2005/2006.

PROJETO ARARIBÁ. Geografia. $7^{\circ}$ ano. $3^{\circ}$ edição. São Paulo: ed. Moderna, 2016.

RESENDE, V. B. de. Fracasso e Sucesso Escolar: Os dois lados da moeda. In: GOMES, M. de F. C. Dificuldades de Aprendizagem na alfabetização. $2^{\mathrm{a}}$ ed. Belo Horizonte: Autêntica, 2000 .

Artigo recebido em: 09/11/2019. Artigo aceito em: 22/12/2019. 